\title{
Visual disturbances during pregnancy caused by central serous choroidopathy
}

\author{
J. R. M. CRUYSBERG AND A. F. DEUTMAN \\ From the Institute of Ophthalmology, University of Nijmegen, Nijmegen, The Netherlands
}

SUMmARY Three patients had during pregnancy visual disturbances caused by central serous choroidopathy. One of them had a central scotoma in her first and second pregnancy. The 2 other patients had a central scotoma in their first pregnancy. Symptoms disappeared spontaneously after delivery. Except for the ocular abnormalities the pregnancies were without complications. The complaints can be misinterpreted as pregnancy-related optic neuritis or compressive optic neuropathy, but careful biomicroscopy of the ocular fundus should avoid superfluous diagnostic and therapeutic measures.

Central serous choroidopathy (previously called central serous retinopathy) is a spontaneous serous detachment of the sensory retina due to focal leakage from the choriocapillaris, causing serous fluid accumulation between the retina and pigment epithelium. This benign disorder occurs in healthy adults between 20 and 45 years of age, who present with symptoms of diminished visual acuity, relative central scotoma, metamorphopsia, and micropsia. Males are affected more commonly than females by at least 10 to one.' Most eyes have a complete visual recovery over a variable period of time. The cause of the condition is unknown.

Although this disease usually affects males, we have observed central serous choroidopathy in pregnant females. The course of symptoms in these patients made a causal relationship with pregnancy probable.

\section{Case reports}

CASE 1

A 34-year-old woman (gravida 2) noted visual blurring and a relative central scotoma in the left eye when she was 28 weeks pregnant. Ophthalmological examination was performed 10 weeks later, on 17 March 1981 . Visual acuity was $6 / 5$ in the right eye and $6 / 6$ in the left eye. Indirect ophthalmoscopy and slit-

Correspondence to J. R. M. Cruysherg. MD, University of Nijmegen, Institute of Ophthalmology. Philips van Leydenlaan 15. Nijmegen. The Netherlands. lamp biomicroscopy of the fundus with a Goldmann contact lens showed a serous detachment of the neurosensory retina in the macular region of the affected left eye. Fluorescein angiography was not performed because of pregnancy. In her first pregnancy the patient had consulted an ophthalmologist on 13 June 1977 for exactly the same symptoms, which had disappeared spontaneously after delivery. Except during pregnancy the patient never had visual complaints.

Delivery was 5 days later. Without treatment the central scotoma and serous detachment disappeared within 2 weeks. Both pregnancies had been normal from the obstetrical point of view.

CASE 2

A 27-year-old woman (gravida 1) noted a relative central scotoma in her right eye when she was 20 weeks pregnant. Ophthalmological examination on 18 July 1980 disclosed a serous detachment of the sensory retina in the macular region of the right eye. The macular lesion was evident by the slit-lamp microscope and Goldmann contact lens, so fluorescein angiography was not performed in pregnancy. The visual acuity was $6 / 30$ in the right eye after correction $(S+2 \cdot 0)$ of hypermetropia and $6 / 6$ in the emmetropic left eye. Without treatment the serous detachment persisted during pregnancy.

After delivery the first ocular examination was performed on 6 March 1981. The visual complaints had disappeared, and visual acuity had returned to $6 / 6$ without correction. There was no evidence of 
serous detachment of the sensory retina. The macula of the right eye showed a slight granularity of the pigment epithelium. The pregnancy had been uneventful from the obstetrical point of view.

\section{CASE 3}

A 32-year-old woman (gravida 1) noted blurred vision and central scotoma in her right eye when she was 32 weeks pregnant. Ophthalmological examination on 14 August 1980, one week after the initial symptoms, disclosed a serous detachment of the sensory retina in the macular region of her right eye. Visual acuity was $6 / 30$ in the right eye and $6 / 6$ in the left eve.

After delivery on 29 September visual complaints disappeared spontaneously. On 27 November 1980 ophthalmological examination disclosed visual acuity $6 / 6$ in the right eye. There was still some metamorphopsia (Amsler grid), but the serous detachment had disappeared. The pregnancy had been normal from the obstetrical point of view.

\section{Discussion}

The occurrence of central serous choroidopathy in 4 pregnancies of these 3 patients, and the spontaneous recovery after delivery, suggested a causal relationship of the disorder and pregnancy. Chumbley and Frank $^{2}$ reported central serous retinopathy in a 34year-old woman during 4 consecutive pregnancies. with remission after delivery or spontaneous abortion. The authors suggest that a hormonal agent, which increases in concentration during pregnancy, is one possible causative factor in this disease. However, since the disorder is more common in men. and usually unilateral, other systemic and ocular factors must play a role.

One of the changes in a normal pregnancy is an increase of plasma volume and total blood volume. Probably circulatory changes in the choriocapillaris can provoke central serous choroidopathy in predisposed eyes. The importance of the ocular factor is suggested by the fact that in consecutive pregnancies the relapse of central serous choroidopathy occurred in the same eye.

Fastenberg et al. ${ }^{3}$ found predominantly abnormal choroidal vascular patterns in toxaemia of pregnancy, implicating choroidal vascular insufficiency as the basis for secondary retinal detachments seen in this complication. However, our patients had a normal pregnancy from the obstetrical point of view, without signs of toxaemia.

It is of the utmost importance to distinguish the correct causes of visual disturbances and field defects during pregnancy. In all cases a careful examination of the ocular fundus is necessary to exclude a retinal cause. The central scotoma can be misinterpreted as a result of optic neuritis. The association of optic neuritis and pregnancy has previously been suggested. ${ }^{4-7}$ Visual disturbances during pregnancy have been reported as a result of the expansion of intracranial tumours (meningiomas, pituitary adenomas, and craniopharyngiomas) owing to hormonal changes. ${ }^{5-11}$ As in our patients with central serous choroidopathy the spontaneous recovery of visual functions after delivery has been described in patients with intracranial tumours. ${ }^{9-12}$

If central serous choroidopathy is the cause of visual disturbances during pregnancv. its correct diagnosis may avert superfluous diagnostic and therapeutic measures.

\section{References}

1 Gass JDM. Stereoscopic Atlas of Macular Diseases: A funduscopic and Angiographic Presentation. St Louis: Mosby. 1977: 28.

2 Chumbley LC. Frank RN. Central serous retinopathy and pregnancv. Am J Ophthalmol 1974: 77: 158-6().

3 Fastenberg DM. Fetkenhour CL. Choromokos E. Shoch DE. Choroidal vascular changes in toxemia of pregnancy. $A m J$ Ophthalmol 1980: 89: 362-8.

4 Kogan JA. Retrobulbar neuritis during pregnancy. Sovet Vestn Oftalmol 1934: 5: 503-5.

5 Hagedoorn A. The chiasmal syndrome and retrobulbar neuritis in pregnancv. Am J Ophthalmol 1937: 20: 690-9.

6 Caderas de Kerleau J. Cazaban R. Étude clinique des atteintes du nerf optique au cours de la grossesse. Presse Méd 1952; 60: 943-4.

7 Caderas de Kerleau J. Durand G. Cazaban R. Névrite rétrobulbaire gravidique aggravée après l'accouchement. Apparition de lésions choriorétiniennes deux mois après. Bull Soc Ophtalmol France 1952: 52: 319-21

8 Enoksson P. Lundberg N. Sjöstedt S. Skanse B. Influence of pregnancy on visual fields in suprasellar tumours. Acta Psvchiatr Neurol Scand 1961; 36: 524-38.

9 Swver GIM. Little V. Harries BJ. Visual disturbance in pregnancy after induction of ovulation. Br Med J 1971: iv: 90-1.

10 Corbey RS. Cruysberg JRM. Rolland R. Visual abnormalities in a pregnancy following bromocriptin medication. Obstet Gynecol 1977: 50: 69s-71s.

11 Lamberts SWJ. Seldenrath HJ. Kwa HG. Birkenhäger JC. Transient hitemporal hemianopsia during pregnancy after treatment of galactorrhea-amenorrhea svndrome with bromocriptine. J Clin Endocrinol Metah 1977; 44: 180-4.

12 Husami N. Jewelewicz R. Vande Wiele RL. Pregnancy in patients with pituitary tumors. Fertil Steril 1977: 28: 920-5. 